\title{
Assessing tree-related microhabitat retention according to a harvest gradient using tree-defect surveys as proxies in Eastern Canadian mixedwood forests
}

\author{
by Maxence Martin 1,2,"* and Patricia Raymond²,3
}

\begin{abstract}
Tree-related microhabitats (hereafter "TreMs") play a key role in forest biodiversity. However, harvesting may cause their erosion. In North America, knowledge about TreMs is still lacking but defect surveys are largely available in managed forests. The objectives of our study were: (1) to demonstrate that defect surveys can be a reliable resource to identify TreMs; and, (2) to evaluate the capacity of silvicultural treatments to maintain TreM abundance and diversity according to a harvest gradient. To achieve these objectives, we identified TreMs from a defect survey performed the year a harvest gradient was applied to 20 plots, including uncut control, shelterwood treatments removing 50\%, $43 \%$ and $36 \%$ of basal area, and clearcut (4 plots/treatment). The density and composition of TreMs were then compared based on treatments. Overall, $38 \%$ of defects actually corresponded to TreMs, confirming that tree-defects can be used as TreM proxies. Bark loss was the most abundant TreM. While there was practically no TreM in clearcuts, all shelterwood treatments initially maintained TreM diversity and density at the same values found in uncut control plots. Shelterwood systems, especially those maintaining a continuous cover, could therefore prove helpful to sustain TreMs and their biodiversity in managed forests.
\end{abstract}

Keywords: mixedwood; wildlife habitat; forest biodiversity conservation; monitoring; tree structure; ecosystem management; disturbance-based management; multi-aged silviculture; Femelschlag; continuous cover; tree vigour

\section{RÉSUMÉ}

Les microhabitats des arbres (dorénavant "TreMs ») jouent un rôle clé dans la biodiversité forestière. Cependant, l'exploitation forestière peut causer leur déclin. Peu d'information est disponible sur les TreMs en Amérique du Nord, mais les inventaires de défauts sont courants. Nos objectifs étaient ainsi : 1) démontrer que les inventaires de défauts permettent d'identifier les TreMs et 2) évaluer la capacité des traitements forestiers à maintenir la diversité et la densité des TreMs selon un gradient de récolte. Nous avons identifié les TreMs à partir d'un inventaire de défauts réalisé l'année suivant l'application d'un gradient de récolte (témoin, coupes partielles retirant $50 \%, 43 \%$ et $36 \%$ de la surface terrière, coupe totale) dans 20 placettes (4 placettes/traitement). Nous avons ensuite comparé la densité et la composition en TreMs selon les traitements. 38\% des défauts correspondaient à des TreMs, confirmant le lien entre défauts et TreMs. Le bois sans écorce était le TreM le plus abondant. Les TreMs étaient presque absents des coupes totales, mais de densité et diversité équivalentes entre le témoin et les coupes partielles. Ces types de traitements, notamment ceux conservant un couvert continu, pourraient donc aider à conserver les TreMs dans les forêts aménagées.

Mots clés: forêt mixte; habitat naturel; conservation de la biodiversité forestière; inventaire; structure des arbres; aménagement écosystémique; aménagement basé sur les perturbations; sylviculture de la futaie irrégulière; Femelschlag; couvert permanent; vigueur des arbres

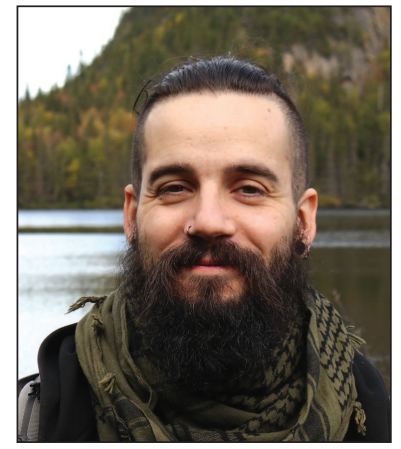

Maxence Martin

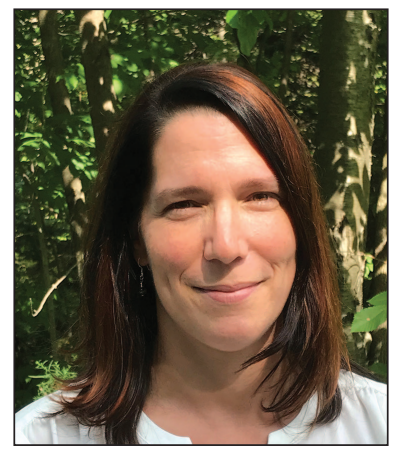

Patricia Raymond

\footnotetext{
${ }_{1}^{1}$ Département des sciences fondamentales, Université du Québec à Chicoutimi, 555 boul. de l'Université, Chicoutimi, Quebec, G7H2B1, Canada* Corresponding author: maxence.martin1@uqac.ca

${ }^{2}$ Centre d'étude de la forêt, Université du Québec à Montréal, P.O. Box 8888, Centre-ville Station, Montréal (QC) H3C 3P8, Canada.

${ }^{3}$ Direction de la recherche forestière, Ministère des Forêts, de la Faune et des Parcs du Québec, 2700 rue Einstein, Quebec, G1P 3W8, Canada
} 


\section{Introduction}

Finding balance between conflicting economic and environmental objectives is a challenge commonly faced by forest managers (Bengston 1994; Bauhus et al. 2009; Puettmann et al. 2009). In conventional silvicultural systems, each action performed in a forest stand aims to improve its commercial quality. Therefore, trees with a high risk of dying before the next intervention or with a low economic value are first removed through thinning or selection cut (Majcen et al. 1990; Nyland 2002). However, by removing in priority trees that are senescent, wounded or crooked, conventional silvicultural practices have, as a downside, the removal of trees with the highest ecological value (Darveau and Desrochers 2001; Michel and Winter 2009; Dieler et al. 2017). As a result, management strategies focussing only on high-quality timber production can eventually lead to biodiversity issues (Puettmann et al. 2009; Dieler et al. 2017).

Tree-related microhabitats (hereafter "TreM") are "distinct, well delineated structure occurring on living or standing dead trees, that constitutes a particular and essential substrates or life site for species or species communities during at least a part of their life cycle to develop, feed, shelter or breed" (Larrieu et al. 2018). TreMs play a key role in forest biodiversity, along with other elements like dead wood or stand structural complexity (Darveau and Desrochers 2001; Stokland et al. 2012; Gao et al. 2015). Yet they have strongly decreased in Europe because of management strategies based on the continuous improvement of stem quality (Winter and Möller 2008; Larrieu et al. 2012; Dieler et al. 2017). Cracks, cavities or saproxylic fungi are examples of TreMs that are perceived as defects by foresters, justifying the removal of host trees for these structures (Havreljuk et al. 2014). The decline in TreMs is thus a relevant example of the difficulty in finding balance between stand commercial value and biodiversity conservation when managing forests with conventional silvicultural systems. Accordingly, major efforts were made in Europe over the last decades to improve the recognition and understanding of TreMs (Larrieu et al. 2018). As a result, active strategies for their protection were integrated into European sustainable management policies (European Commission 2015).

In North America, cavities are virtually the only TreM studied and considered in management strategies (Kenefic and Nyland 2007; Bauhus et al. 2009). To date, research studies about other types of TreMs have been restricted to Northwestern America (Michel and Winter 2009). This can be explained by the fact that cavities are particularly important for many species of birds, mammals, insects, arachnids and fungi, yet seriously threatened by forest management (DeGraaf and Shigo 1985; Ouellet-Lapointe et al. 2012). However, TreM-dependent species vary based on the type of TreM. For instance, species requiring cavities do not require dead branches or bark loss to thrive (Winter and Möller 2008; Larrieu et al. 2018). Hierarchizing TreMs is thus unsuitable, as they are complementary drivers of forest biodiversity. Overall, a better understanding of the diversity and importance of TreMs is fundamental to ensure a sustainable forest management.

Currently, the dominant forest management paradigms aim to include environmental objectives in active management strategies ( Lindenmayer et al. 2008; Sarr and
Puettmann 2008; Dieler et al. 2017). In managed forests, silvicultural systems maintaining a continuous cover can preserve old-growth attributes and stand complexity and serve as promising systems to conciliate wood production and biodiversity protection (Bauhus et al. 2009; Raymond et al. 2009; Gauthier et al. 2018). However, even in continuous-cover systems, TreMs may progressively decline because they are recognized as defects that deplete stand quality by foresters instead of TreMs. In the absence of TreM monitoring, a TreM decline similar to that observed in Europe could occur in North American forests, especially in areas under intensive forest management.

Unlike TreM surveys, defect surveys are very common in North America because they are an essential tool for forest managers. Moreover, a significant part of the elements described in defect typology are likely to be identified as TreMs. For these reasons, defect surveys could be efficient TreM proxies in regions where this knowledge is lacking. By combining defect and TreM surveys, the most efficient silvicultural systems could actually be identified to achieve balance between stand quality improvement and biodiversity protection. Thus, the first objective of our study was to demonstrate that tree-defect surveys can be a reliable resource to identify tree-related TreMs in the absence of specific TreM surveys. We predicted that a large part of trees considered as defective in surveys are hosts to TreMs. Our second objective was to evaluate the capacity of silvicultural treatments to maintain TreM abundance and diversity according to a harvest gradient. We predicted that silvicultural treatments enabling a higher tree retention can better preserve the abundance and diversity of TreMs. To achieve these objectives, we used the experimental design described by Raymond and Bédard (2017), consisting of balsam fir (Abies balsamea [L.] Mill.)-yellow birch (Betula alleghaniensis Britton) stands under four silvicultural scenarios with a gradient of harvest intensity and where accurate defect surveys were performed.

\section{Materials and methods Study territory}

This study used data from the irregular shelterwood experiment conducted in the Portneuf County (CPI-M1), $80 \mathrm{~km}$ northwest of Québec City, Canada (Raymond and Bédard 2017). This region is characterized by hilly topography with rounded tops (Robitaille and Saucier 1998). The experiment was established in balsam fir-yellow birch stands growing on thin $(<1 \mathrm{~m})$ glacial upslope tills (10\% slope) between $330 \mathrm{~m}$ and $460 \mathrm{~m}$ altitude. The region receives on average $1250 \mathrm{~mm}$ of annual precipitations, with $31 \%$ snowfall. Mean monthly temperatures (1981 to 2010 ) vary from $-14.6{ }^{\circ} \mathrm{C}$ in January to $17.3^{\circ} \mathrm{C}$ in July (using BioSIM; Regniere and Bolstad 1994). The dominant ecotype was classified as balsam fir-yellow birch with thin-to-thick deposits, medium soil texture and mesic drainage (Blouin and Berger 2003). Selected stands had irregular, uneven-aged structures (sensu Smith et al. 1997), with the oldest trees exceeding 150 years, and a majority of trees smaller than $50 \mathrm{~cm}$ at diameter at breast height $(\mathrm{DBH})$. The presence of stumps and dendrochronological evidence of growth release indicates that partial cutting occurred during the 1960s. However, there was no evidence of previous cuts in the stands. Prior to cutting, the mean merchantable basal 
area (BA) was $30 \pm 3.6 \mathrm{~m}^{2} /$ ha composed of $45 \%$ balsam fir, $24 \%$ red spruce (Picea rubens Sarg.), 16\% red maple (Acer rubrum L.) and 12\% yellow birch. The remaining BA included companion species, such as paper birch (Betula papyrifera Marsh.), mountain maple (Acer spicatum L.), pin cherry (Prunus pensylvanica L.f.), striped maple (Acer pensylvanicum L.) and American mountain-ash (Sorbus americana Marsh.).

\section{Experimental design}

The experiment was comprised of four complete randomized blocks, each one testing five silvicultural systems applied on $70 \mathrm{~m} \times 70 \mathrm{~m}$ (0.49 ha) experimental units (EU). Testing was conducted from the less to the most intense harvest: (i) uncut control ( $0 \%$ removal, $30 \mathrm{~m}^{2} /$ ha basal area); (ii) continuous cover irregular shelterwood ("CCIS", with expected 2530 year return intervals, $19 \mathrm{~m}^{2} /$ ha of residual basal area [RBA], no final cut); (iii) extended irregular shelterwood (“EIS", RBA $17 \mathrm{~m}^{2} /$ ha, expected final cut after 30 years); (iv) uniform regular shelterwood ("URS", RBA $15 \mathrm{~m}^{2} / \mathrm{ha}$, expected final cut after 10 years); and (v) clearcut with protection of regeneration and soils (harvest of merchantable trees $>9 \mathrm{~cm}$ DBH using spaced skid trails) (Raymond and Bédard 2017). We delimited the blocks based on location and stand composition (\% merchantable BA in softwoods and hardwoods) before we randomly assigned treatments within the blocks.

Tree marking in shelterwood treatments was based on a combination of harvest priorities related to tree vigour ("MSCR" vigour classification by Boulet 2005) and species composition and diameter. We marked non-vigorous trees to be removed to improve stand quality and short-lived tree species above a specified diameter to prevent short-term mortality (balsam fir $>20 \mathrm{~cm} \mathrm{DBH}$, aspen $>24 \mathrm{~cm}$ and paper birch $>32 \mathrm{~cm})$. Since the experiment aimed to conserve latesuccessional structural attributes, we also marked legacy trees to be retained in each EU: three living legacy trees $>19 \mathrm{~cm}$ $\mathrm{DBH}$, including one veteran of long-lived tree species (i.e., red spruce or yellow birch), one yellow birch seed-tree and one cavity tree (current or potential) or fruit tree (sensu OMNR 2004), as recommended by current guidelines for "adapted silviculture practices" (Déry and Leblanc 2005). Standing dead trees $\geq 20 \mathrm{~cm} \mathrm{DBH}$ were not cut unless they could compromise forest workers' safety (i.e., if located in the vicinity of a marked tree, within a distance equivalent to its height). Cutting was performed during the leafless period of fall 2009.

\section{TreM identification and analysis}

All merchantable trees $(\mathrm{DBH}>9 \mathrm{~cm})$ in $50 \mathrm{~m} \times 50 \mathrm{~m}$ central study plot within each EU were numbered, mapped and characterized for species, $\mathrm{DBH}$ and a combined risk (i.e. vigour) and wood product class (i.e., potential sawlog or not) (Majcen et al. 1990) before and after the cut. We used the Boulet (2005) tree-defect typology to assess the first prediction that a large part of trees considered as defective in surveys are hosts to TreMs. The survey was performed the year following the cut. Since no defect evaluation was conducted prior to the cut, we assumed that the precut defect distribution was similar between the plots. Indeed, as the sampling design initially aimed to compare different silvicultural treat- ments, pre-harvest stand commercial value should have been similar (i.e., the stand defects composition) among the different treatments. In addition, the plot size is relatively large in comparison to standard sizes in Québec $(20$ x 20 m, MFFP 2016), limiting the potential biases due to the sampling of a non-representative plot.

All defects were then identified and recorded in the study plots and their characteristics were compared with the Larrieu et al. (2018) typology, since their research provided the most recent and complete TreM typology at the time of this study. When the characteristics of a tree defect class matched the characteristics of a TreM, we considered that defect class as such ("TreMs"). For example, the Boulet (2005) "defect class", defined as "circular or elongated hole on the trunk with a diameter superior or equal to $10 \mathrm{~cm}$ " also corresponds to the Larrieu et al. (2018) TreM "trunk rot-hole" defined by a cavity with an opening $10 \mathrm{~cm}$ or over in diameter. In contrast, the defect classes that did not correspond to any TreM types were considered as "non-TreM defects." Trees without any non-TreM defects or TreMs corresponded to the "no defect" group. However, the size or number thresholds used by Boulet (2005) are often different than those suggested by Larrieu et al. (2018). Therefore, the thresholds were adapted to discriminate between TreMs and non-TreM defects. Nevertheless, we aimed to define biologically consistent and conservative thresholds in order to ensure the biological values of our definition of TreMs. In addition, the Boulet (2005) classification identifies for each tree the defects that most depreciates tree vigour and sawlog quality. Thus, and at the opposite of common TreMs surveys, (e.g., Winter and Möller 2008; Vuidot et al. 2010; Larrieu et al. 2012), a maximum of one defect has been recorded for each tree.

To assess the second prediction that silvicultural treatments enabling a higher tree retention better preserve the abundance and diversity of TreMs, an analysis of variance (ANOVA) was used with random effects. For each ANOVA, the treatments were used as a fixed factor and the blocks as a random factor. Firstly, an ANOVA was performed for each defect group (TreM, non-TreM defect, no defect) using density (n. trees/ha) as dependent variable. Secondly, an ANOVA was performed for each TreM class using density as the dependent variable. Finally, we performed ANOVA to compare the diversity of TreM classes among cutting treatments with the Shannon diversity index (Shannon and Weaver 1949). For all these analyses, a post-hoc Tukey test was performed (Kutner et al. 2004). When necessary, we performed data transformation (square-root, $\log 2$ or outlier removal) to meet ANOVA requirements. An ANOVA was not carried out for TreM classes that had fewer than 20 observations in all plots combined (i.e., bark shelter, fork split, epicormic shoots, sap run and heavy resinosis, and burr).

Statistical analyses were completed using R-software, version 3.3.1 (R Core Team 2016) with the nlme (Pinheiro et al. 2016), emmeans (Russel 2018) and ggplot2 (Wickham 2016) packages based on $\alpha=0.05$.

\section{Results}

\section{TreM identification}

Among the defects inventoried in the survey (Appendix S1), 13 TreM classes and 10 non-TreM defect classes were identi- 
Table 1. Classification of defects by type, TreM category and class, and related thresholds according to Boulet et al. (2004) and Larrieu et al. (2018) typologies. Note that Larrieu et al. (2018) did not propose any thresholds for non-TreM defects. *Potential TreM users were defined according to the Larrieu et al. (2018) literature review.

\begin{tabular}{|c|c|c|c|c|c|c|c|}
\hline $\begin{array}{l}\text { Defect } \\
\text { group }\end{array}$ & Category & Class & Code & Boulet (2005) & Larrieu et al. (2018) & Comments & Potential users ${ }^{*}$ \\
\hline & Cavity & $\begin{array}{l}\text { Trunk cavity } \\
\text { or rot-hole }\end{array}$ & TCR & $\begin{array}{l}\text { Any origin, } \\
\varnothing>10 \mathrm{~cm}\end{array}$ & $\begin{array}{l}\text { All } \emptyset \text { if woodpecker- } \\
\text { origin; } \emptyset>10 \mathrm{~cm} \text { in } \\
\text { other cases }\end{array}$ & $\begin{array}{l}\text { No indication } \\
\text { of cavity origin } \\
\text { in the defect }\end{array}$ & $\begin{array}{l}\text { Mammals, birds, } \\
\text { amphibians, } \\
\text { insects, arachnids, } \\
\text { typology } \\
\text { bryophytes, fungi, } \\
\text { lichens }\end{array}$ \\
\hline & & $\begin{array}{l}\text { Trunk base } \\
\text { rot-hole }\end{array}$ & TBR & $\begin{array}{l}\text { Cavity or scar on } \\
\text { the trunk stump; } \\
\text { no threshold }\end{array}$ & $\begin{array}{l}\text { Ground contact, } \\
\varnothing>10 \mathrm{~cm}\end{array}$ & $\begin{array}{l}\text { Partially rotten } \\
\text { scars and un- } \\
\text { rotten scars } \\
\text { grouped under } \\
\text { the same defect } \\
\text { classes in the } \\
\text { typology }\end{array}$ & $\begin{array}{l}\text { Mammals, birds, } \\
\text { amphibians, } \\
\text { insects, arachnids, } \\
\text { bryophytes, fungi, } \\
\text { lichens }\end{array}$ \\
\hline & \multirow{5}{*}{ Trunk } & Canker & CAN & $\begin{array}{l}\text { Rot depth } \geq 5 \mathrm{~cm} \text {; } \\
\text { main depreciating } \\
\text { defect }\end{array}$ & $\begin{array}{l}\text { Largest } \varnothing>20 \mathrm{~cm} \text { or } \\
\text { large part of the } \\
\text { trunk covered }\end{array}$ & $\begin{array}{l}\text { No indication of } \\
\text { canker surface in } \\
\text { defect typology, } \\
\text { rot depth as unique } \\
\text { available threshold }\end{array}$ & $\begin{array}{l}\text { Insects, bryophytes, } \\
\text { fungi }\end{array}$ \\
\hline & & Bark shelter & BAS & $\begin{array}{l}\text { Covering at least } \\
\text { one face of the } \\
\text { trunk; main depre- } \\
\text { ciating defect }\end{array}$ & $\begin{array}{l}\text { Gap }>1 \mathrm{~cm} \text {; depth } \\
>10 \mathrm{~cm} \text {; height } \\
>10 \mathrm{~cm}\end{array}$ & $\begin{array}{l}\text { Parameters used by } \\
\text { Larrieu et al. }(2018) \\
\text { absent in Boulet } \\
(2005)\end{array}$ & $\begin{array}{l}\text { Mammals, birds, } \\
\text { gastropods, insects, } \\
\text { fungi }\end{array}$ \\
\hline \multirow[t]{8}{*}{ TreM } & & Bark loss & BAL & $\begin{array}{l}\text { Trunk wounded to } \\
\text { the sapwood; main } \\
\text { depreciating defect }\end{array}$ & $\begin{array}{l}300 \mathrm{~cm}^{2} \text { (A5 format) } \\
\text { of sapwood exposed }\end{array}$ & $\begin{array}{l}\text { Parameters used by } \\
\text { Larrieu et al. }(2018) \\
\text { absent in Boulet } \\
(2005)\end{array}$ & $\begin{array}{l}\text { Mammals, birds, } \\
\text { gastropods, insects, } \\
\text { fungi }\end{array}$ \\
\hline & & Large crack & CRA & $\begin{array}{l}\text { [Length }>1.5 \mathrm{~m} \text { ] } \\
\text { or [length } \leq 1.5 \mathrm{~m}, \\
\text { largest width } \\
\geq 10 \mathrm{~cm} \text {, depth } \\
\geq 5 \mathrm{~cm} \text { ] }\end{array}$ & $\begin{array}{l}\text { Length }>30 \mathrm{~cm} \text {; } \\
\text { width }>1 \mathrm{~cm} \text {; depth } \\
>10 \mathrm{~cm}\end{array}$ & $\begin{array}{l}\text { Length }>1.5 \mathrm{~m} \text { con- } \\
\text { sidered as conser- } \\
\text { vative enough in } \\
\text { comparison with } \\
\text { Larrieu et al. }(2018) \\
\text { thresholds }\end{array}$ & $\begin{array}{l}\text { Mammals, birds, } \\
\text { gastropods, insects, } \\
\text { arachnids, fungi, } \\
\text { lichens }\end{array}$ \\
\hline & & Fork split & FOS & $\begin{array}{l}\text { Not healed, close } \\
\text { to breakage }\end{array}$ & Length $>30 \mathrm{~cm}$ & $\begin{array}{l}\text { Parameters used by } \\
\text { Larrieu et al. (2018) } \\
\text { absent in Boulet } \\
(2005)\end{array}$ & $\begin{array}{l}\text { Mammals, birds, } \\
\text { gastropods, insects, } \\
\text { arachnids, fungi, } \\
\text { lichens }\end{array}$ \\
\hline & \multirow[t]{3}{*}{ Top } & $\begin{array}{l}\text { Dead or } \\
\text { broken branch }\end{array}$ & $\mathrm{DBB}$ & $\varnothing>20 \mathrm{~cm}$ & $\emptyset>10 \mathrm{~cm}$ & $\begin{array}{l}\text { Different diameter } \\
\text { thresholds between } \\
\text { the typologies }\end{array}$ & $\begin{array}{l}\text { Birds, insects, } \\
\text { arachnids, fungi, } \\
\text { lichens }\end{array}$ \\
\hline & & Dead top & DET & $\begin{array}{l}>25 \% \text { of the } \\
\text { crown is dead }\end{array}$ & $\begin{array}{l}\text { Branch } \emptyset>3 \mathrm{~cm} \\
\text { and }>10 \% \text { of the } \\
\text { crown is dead }\end{array}$ & $\begin{array}{l}\text { Different thresholds } \\
\text { and indicators } \\
\text { between the }\end{array}$ & $\begin{array}{l}\text { Birds, insects, } \\
\text { arachnids, fungi, } \\
\text { lichens } \\
\text { typologies }\end{array}$ \\
\hline & & $\begin{array}{l}\text { Epicormic } \\
\text { shoots }\end{array}$ & EPS & $\begin{array}{l}\text { Main depreciating } \\
\text { defect }\end{array}$ & $>5$ twig clusters & $\begin{array}{l}\text { Parameters used by } \\
\text { Larrieu et al. (2018) } \\
\text { absent in Boulet } \\
(2005)\end{array}$ & Birds, arachnids \\
\hline & \multirow[t]{2}{*}{ Small } & Burr & BUR & $\begin{array}{l}\text { Main depreciating } \\
\text { defect }\end{array}$ & Largest $\varnothing>20 \mathrm{~cm}$ & $\begin{array}{l}\text { Parameters used by } \\
\text { Larrieu et al. (2018) } \\
\text { absent in Boulet } \\
(2005)\end{array}$ & $\begin{array}{l}\text { Insects, bryophytes, } \\
\text { fungi }\end{array}$ \\
\hline & & Fungi & FUN & $\begin{array}{l}\text { Any fungi causing } \\
\text { wood decay }\end{array}$ & $\begin{array}{l}\text { Various according } \\
\text { to the fungus } \\
\text { species }\end{array}$ & $\begin{array}{l}\text { Different fungus } \\
\text { species between } \\
\text { Europe and North } \\
\text { America }\end{array}$ & $\begin{array}{l}\text { Gastropods, insects, } \\
\text { arachnids, } \\
\text { bryophytes, fungi }\end{array}$ \\
\hline
\end{tabular}




\begin{tabular}{|c|c|c|c|c|c|c|}
\hline Category & Class & Code & Boulet (2005) & Larrieu et al. (2018) & Comments & Potential users ${ }^{\star}$ \\
\hline & Healed wound & HEW & $\begin{array}{l}\text { Scar of an ancient } \\
\text { wound }\end{array}$ & - & - & - \\
\hline & $\begin{array}{l}\text { Superficial bark } \\
\text { wound }\end{array}$ & BAW & $\begin{array}{l}\text { Trunk wounded } \\
\text { on the bark only }\end{array}$ & - & - & - \\
\hline & $\begin{array}{l}\text { Minor top } \\
\text { mortality }\end{array}$ & LTM & $\begin{array}{l}\leq 25 \% \text { of the crown } \\
\text { is dead }\end{array}$ & - & - & - \\
\hline & Small cavity & SMC & $\emptyset \leq 10 \mathrm{~cm}$ & - & - & - \\
\hline & Shape defect & SHD & $\begin{array}{l}\text { Defect influencing } \\
\text { only tree shape }\end{array}$ & - & - & - \\
\hline \multirow[t]{5}{*}{ Non-TreM Defect } & Small crack & SCR & $\begin{array}{l}\text { Length } \leq 1.5 \mathrm{~m} \text { and } \\
\text { largest width }<10 \mathrm{~cm} \\
\text { or depth }<5 \mathrm{~cm}\end{array}$ & $n^{-}$ & - & - \\
\hline & Clump shoot & CLS & - & - & - & - \\
\hline & Small canker & SCA & $\begin{array}{l}\text { Cover less than one } \\
\text { face of the trunk }\end{array}$ & - & - & - \\
\hline & $\begin{array}{l}\text { Wounde or } \\
\text { rotten root }\end{array}$ & WRR & $\begin{array}{l}\text { Root broken } \\
\text { or rotten }\end{array}$ & - & - & - \\
\hline & Insect holes & INH & $\begin{array}{l}\text { Opening of insect } \\
\text { gallery on the trunk }\end{array}$ & - & - & - \\
\hline No Defect & No defect & NOD & - & - & $\begin{array}{l}\text { No defect or TreM } \\
\text { identified for the tree }\end{array}$ & $e^{-}$ \\
\hline
\end{tabular}

fied (Table 1). Tree TreM classes can be grouped in four overarching categories: cavity, trunk, top and small TreMs. Defects corresponding to TreMs were observed in $26 \%$ of the sampled trees (873 trees). Trees with non-TreM defects made up the most abundant group, $43 \%$ of the sampled trees (1435 trees), followed by trees without any defects, 31\%, (1049 trees). Thus, a great portion of the trees defined by the presence of at least one defect are actually hosts to TreMs (38\%), implying a significant importance for stand biodiversity. Tree-bearing TreMs were more abundant for broadleaved species than for coniferous, while it was the opposite for nonTreM defects and no defect trees (Appendix S2). The DBH of trees hosts to TreMs varied strongly depending on tree species and TreM class (Appendix S3).

The most abundant TreM class was bark loss (mean density: 43 trees/ha), while the least abundant were epicormic shoots and fork splits (0.2 trees/ha and 0.1 trees/ha, respectively). Other TreM mean densities ranged from 14 trees/ha (dead top) to 0.4 trees/ha (bark shelter). For non-TreM defects, the most abundant class was bark wound (56 trees/ha), and the less abundant class was clump shoots (4 trees/ha). Thus, there was a strong variation among classes for both TreMs and non-TreM defects. In addition, most of the superficial bark wound (83\%) corresponded to cracks on balsam fir bark, indicative of root rot.

Effects of silvicultural treatments on TreM tree density

Tree density differed among treatments for all defect groups: TreMs $(p<0.001)$, non-TreM defects $(p<0.001)$ and no defect $(p<0.001)$. Overall, each defect group was more abundant in the control than in the clearcut treatment, while they did not differ among the three shelterwood treatments (Fig. 1). Shelterwood treatments maintained a mean TreM density equivalent to that observed in the control (e.g., 124 trees/ha in control, from 85 to 106 trees/ha in shelterwood treatments and 27 trees/ha in the clearcut). In contrast, shelterwood treatments decreased the density of trees showing non-TreM defects and defect-free trees, but the reduction was much less important than with the clearcut (e.g., 310 defect non-TreM trees/ha and 211 no-defect trees/ha in control, from 119 to 156 defect non-TreM trees/ha and 85 to 117 no-defect trees/ha in shelterwood treatments, 11 defect non-TreM trees/ha and 23 no-defect trees/ha in the clearcut). The only exception was for the no defect free trees in extended regular shelterwood treatments, with a density similar to that observed in the clearcut.

\section{Effects of silvicultural treatments on TreM diversity and com- position}

Comparison among the treatments using the Shannon index showed that shelterwood treatments had a diversity of TreMs equivalent to the control and, on average, three times greater than in the clearcut ( $p<0.05$; Fig. 2). Overall, we found differences in density among treatments for five TreM classes: trunk cavity or rot-hole, bark loss, large crack, dead or broken branches and dead top (Table 2). Dead tops and large cracks were more abundant in the control treatment than in any other treatments (respectively $p<0.001$ and $p<0.05$; Fig. 3 ). Dead top density was also higher in uniform regular shelterwood than in irregular shelterwood treatments and the 

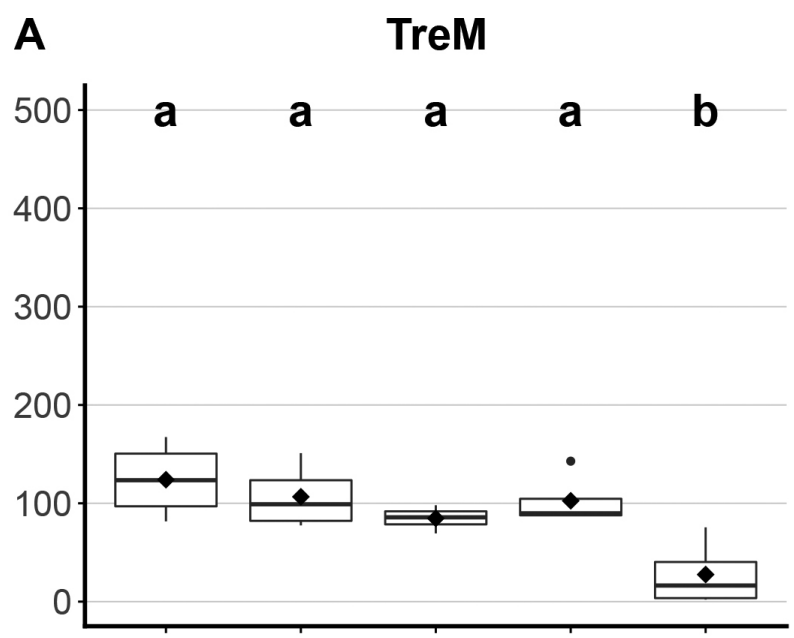

B Non-TreM defect
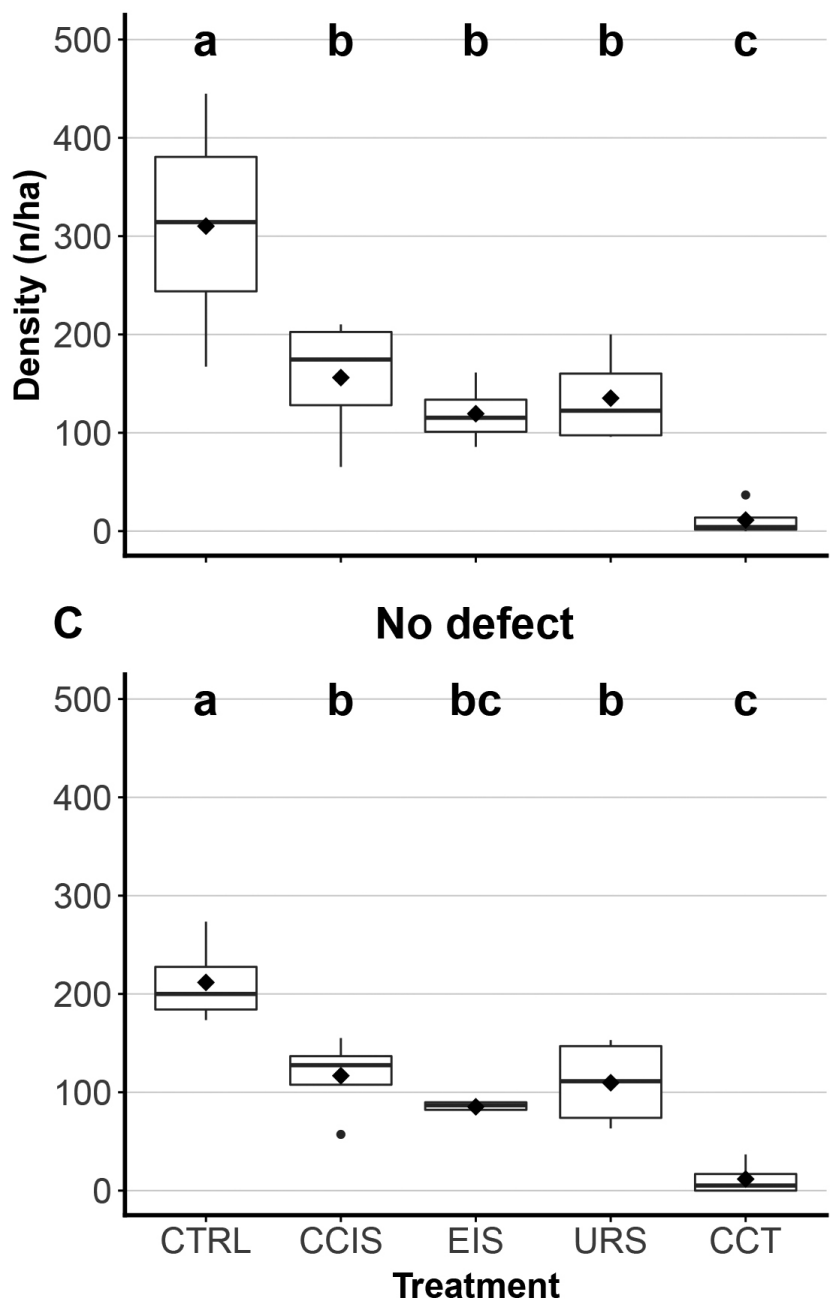

Fig. 1 Boxplots of tree density by treatment for (A) TreMs, (B) non-TreM defects and $(C)$ no defect. Letters represent significantly different values and diamonds mean values. CTRL: control; CCIS: continuous irregular shelterwood cutting (RBA: $19 \mathrm{~m}^{2} / \mathrm{ha}$ ); EIS: extended irregular shelterwood cutting (RBA: $17 \mathrm{~m}$ /ha); URS: uniform regular shelterwood cutting (RBA: 15 $\mathrm{m}^{2} / \mathrm{ha}$ ); CCT: clearcut clearcut. Extended irregular shelterwood was the only treatment with the same density of large cracks as the clearcut. Trunk cavity or rot-hole was more abundant in the control than in the clearcut $(p<0.05)$. Bark loss was greater in the three shelterwood treatments than in the clearcut, but not greater than in the control $(p<0.05)$. Dead and broken branches were in higher density in the continuous irregular shelterwood than in the clearcut $(p<0.05)$. Finally, there was no significant variation in the density of trunk-base rot-hole, canker and fungi TreMs. The mean density of tree bearing fungi was higher in the control in comparison to the other treatments, but this result was mostly due to two outliers in control plots. When the outliers influence was smoothed through data transformation, there was no difference among treatments.

\section{Discussion}

The assessment of tree-related TreMs using the Boulet (2005) defect survey method showed a significant correspondence between the defect classes and TreMs. The study revealed that numerous defect trees were actually TreM hosts and may have an important biological value for the stands. We also found that the overall density of TreM-host trees and their diversity in shelterwood treatments were similar to those measured in the control, regardless of the harvest intensity. However, the small shifts observed in TreM composition indicate that some TreM classes like large cracks could be replaced by others like bark loss over time in managed stands.

\section{Tree-defects as relevant TreM proxies}

To our knowledge, this is the first time that TreMs and tree defects are directly linked. The results hence support the evidence of a relationship that has often been evoked in the past. Previous studies hypothesized that the perception of TreMs as defects by forest managers caused their erosion in managed stands (Winter and Möller 2008; Michel and Winter 2009; Regnery et al. 2013). Similarly, Havreljuk et al. (2014) proposed to maintain defect-bearing trees to meet biodiversity goals in management planning. This implies an acknowledgement of the contribution of defective trees to forest biodiversity. However, achieving biodiversity conservation objectives requires the integration of TreM objectives in current management practices (Dieler et al. 2017). For this reason, the link between TreMs and defects needs to be clarified and acknowledged by both forest managers and ecologists because defects and TreMs are often the two sides of the same coin.

Overall, the thresholds used for our typology based on Boulet (2005) were rarely similar to those suggested by Larrieu et al. (2018). However, they were often more conservative. The most striking example is the "trunk-base rot-hole" class 
for which the corresponding Boulet (2005) defect classes are divided throughout a $60 \mathrm{~cm}$-diameter threshold, much larger than the $10 \mathrm{~cm}$-diameter suggested by Larrieu et al. (2018). Because of this large gap between the two thresholds, we retained no size threshold for this TreM. Thus, no additional restriction was added for this class and all trunk-base rot-hole defects using Boulet (2005) were considered as TreMs. Similarly, the Boulet (2005) thresholds are more conservative than the Larrieu et al. (2018) thresholds for woodpecker breeding cavities, dead or broken branches and dead tops. This implies that some defects nonretained as TreM in this study still could have a significant importance for biodiversity. Furthermore, specific size or number thresholds were sometimes absent in the Boulet (2005) defect classes, especially for burrs, sap runs/heavy resinosis, fungi and epicormics shoots. However, it was assumed that if such defect classes were considered as the main depreciating ones, it was likely to achieve the Larrieu et al. (2018) thresholds. The Larrieu et al. (2018) typology was also defined for European temperate forests and it was also possible that some of these thresholds are not relevant in northeastern American forests. Finally, not all TreMs are defects, such as bird nests or epiphytic plants (Vuidot et al. 2010; Michel et al. 2011; Larrieu et al. 2018). Therefore, it is likely that nondefects TreMs have not been identified in the stands in this study. Nevertheless, we found that many trees that could be classified as defective by Boulet (2005) shared similar TreM characteristics described by Larrieu et al. (2018), implying that such a typology of tree defects could be used as a proxy for TreM surveys.

The density variation in TreM class is consistent with studies in European broadleaved or mixedwood forests. For example, TreM classes identified by Möller et al. (2008) ranged from 0.5 to $62 \mathrm{TreMs} / \mathrm{ha}$, while those identified by Larrieu et al. (2012) ranged from 1 to $35 \mathrm{TreMs} / \mathrm{ha}$. However, the defect survey method of Boulet (2005) used in this study only considered one defect or TreM for each tree, i.e., the most depreciating one, while tree hosts of more than one TreM are common, especially for the largest ones (Vuidot et al. 2010; Larrieu et al. 2014). It is therefore likely that TreM density in the stands in this study is superior to the density of TreM host trees. In addition, the Boulet (2005) methodology only survived live trees, while dead trees are an important TreM resource (Vuidot et al. 2010; Larrieu et al. 2012; Siitonen 2012). Standing dead trees that presented no risk for workers were maintained in each treatment and were still abundant in the study plots (Martin 2014). This implies that snags were an important contributor to TreM richness and diversity.

Potential of silvicultural systems using partial cuts to maintain TreMs in managed forests

By removing almost all the merchantable trees, clearcutting cause a significant decrease in TreM abundance. They also strongly limit their recruitment in future decades. TreM density increases with stand age or individual tree size, and often

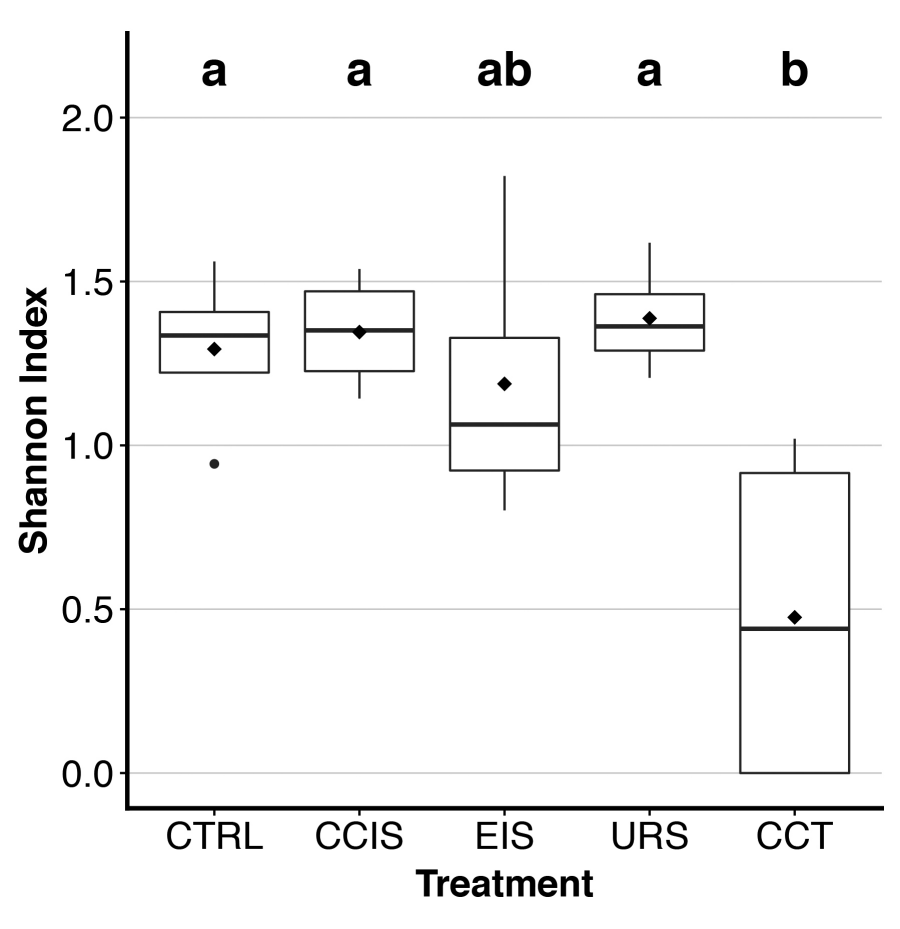

Fig. 2 Boxplot of Shannon index values by TreM classes and cutting treatments. Letters represent significantly different values and diamonds, mean alues.CTRL: control; CCIS: continuous irregular shelterwood cutting (RBA: $9 \mathrm{~m}^{2} / \mathrm{ha}$ ); ElS: extended irregular shelterwood cutting (RBA: $17 \mathrm{~m}^{2} / \mathrm{ha}$ ); RS: uniform regular shelterwood cutting (RBA: $15 \mathrm{~m}^{2} / \mathrm{ha}$ ); CCT: clearcut") requires minimum tree size to appear or to fulfill their ecological roles (Michel et al. 2011; Regnery et al. 2013; Larrieu et al. 2014). For example, woodpeckers mainly excavate cavities in trees with a DBH $\geq 20 \mathrm{~cm}$ (Holloway et al. 2007; Vaillancourt et al. 2008). Consequently, the TreM density and quality in clearcut stands will remain low over decades, as they are mostly constituted of young and small trees (Larrieu et al. 2017). Moreover, in clearcutting systems, stands are often harvested at a relatively young age compared with natural stand dynamics (Bergeron et al. 2002). This implies that TreM density, recruitment and functionality are restricted in these stands, as trees are cut before they reach an age or a size favourable to TreM development. Hence, clearcutting is the least suitable forest treatment for a sustainable and efficient TreM management.

In contrast, shelterwood systems have a good potential to maintain TreM density and diversity similar to those observed in unmanaged stands. Despite a rather narrow range of residual basal areas tested in the shelterwood treatments, each of these treatments had a specific impact on postharvest stands structure and regeneration (Raymond and Bédard 2017). Thus, the similarity in TreM abundance and diversity between the shelterwood treatments seemingly mainly results from the prior harvest of non-TreM defects bearing trees. However, in the very long-term, the cumulative effect of successive harvests and thinnings can decrease TreM abundance and diversity, as observed in Europe (Larrieu et al. 2018). The high TreM abundance observed in this study may be explained by the more recent management history in 
Table 2. Summary of treatment effects on tree density and Shannon index values by defect group and TreM class. A dash indicates that no analysis was performed for a given TreM because of low abundance (i.e., less than 20 records)

\begin{tabular}{|c|c|c|c|c|c|}
\hline \multirow[b]{2}{*}{$\begin{array}{l}\text { Defect } \\
\text { Group }\end{array}$} & \multirow[b]{2}{*}{ Category } & \multirow[b]{2}{*}{ Class } & \multicolumn{3}{|c|}{ Analysis } \\
\hline & & & Dependent Variable & Transformation & $\begin{array}{c}\text { ANOVA } \\
p \text {-value }\end{array}$ \\
\hline TreM & All & All & Density & No transformation & $<0.001$ \\
\hline Non-TreM defect & All & All & Density & No transformation & $<0.001$ \\
\hline No defect & All & All & Density & No transformation & $<0.001$ \\
\hline \multirow[t]{14}{*}{ TreM } & Cavity & Trunk cavity or rot-hole & Density & No transformation & $<0.05$ \\
\hline & & Trunk base rot-hole & Density & Square root & n.s. \\
\hline & Trunk & Canker & Density & Square root & n.s. \\
\hline & & Bark shelter & - & - & - \\
\hline & & Bark loss & Density & Square root & $<0.05$ \\
\hline & & Large crack & Density & - & $<0.05$ \\
\hline & & Fork split & - & - & - \\
\hline & Top & Dead or broken branch & Density & No transformation & $<0.05$ \\
\hline & & Dead top & Density & Outlier removal (2 units) & $<0.001$ \\
\hline & Small & Epicormic shoots & - & - & - \\
\hline & & Sap run/heavy resinosis & - & - & - \\
\hline & & Burr & - & - & - \\
\hline & & Fungi & Density & $\log 2$ & n.s. \\
\hline & All & All & Shannon index & No transformation & $<0.05$ \\
\hline
\end{tabular}

North American forests. Furthermore, future entries will also greatly influence stand structural characteristics. In the continuous irregular shelterwood system, stand structure is expected to remain complex with the constant presence of trees of various sizes. However, uniform and extended shelterwood systems will have their overstory harvested once the regeneration is established (e.g., at 10 and 30 years), leading to either even-aged or two-aged stand structures. Therefore, even if these shelterwood systems provide better TreM conservation than clearcuts in the short-term, their mediumterm effects will be similar. By maintaining old and mature trees, the continuous irregular shelterwood system is the one with the best potential for sustainable TreM management (Bauhus et al. 2009; Raymond et al. 2009). Nevertheless, silvicultural systems likely to maintain a continuous forest cover can eventually cause a decrease in large trees or TreM densities in the absence of specific retention conditions for old-growth forest attributes (Dieler et al. 2017). However, TreM recruitment is also a dynamic process (Regnery et al. 2013), and densities found in harvested stands can continue to change in the future. The results of our study only provide a picture of the stands immediately after harvesting; but it is likely that TreMs will differ at the time of the next entry. For these reasons, long-term monitoring of the cumulative effects of partial cuts in North American forests will be necessary to ensure that they do not result in TreM depletion.

Because large cracks are the most depreciating defect for $\log$ quality along with fungi, this TreM was the one that decreased the most after shelterwood cutting (54\% to $74 \%$ less abundant than the control) (Havreljuk et al. 2014). Still, with approximately 5.6 trees/ha, the density of trees with large cracks in the stands under shelterwood cuts was close to the density observed in European or northwestern American forests, ranging from 4 to 13 trees/ha in the reference stands (Winter and Möller 2008; Michel and Winter 2009; Larrieu et al. 2012). Species using this TreM, such as bats (Larrieu et al. 2018), should not be affected by the decrease; however, further study would be necessary to assess this observation. Conversely, the density of trees with bark loss slightly increased in shelterwood treatments. This TreM is often more abundant in managed than in unmanaged forests (Winter and Möller 2008; Vuidot et al. 2010; Larrieu et al. 2012), probably because they may result from logging wounds. Similarly, some treatments favoured particular TreM classes, such as dead top in the uniform regular shelterwood cutting system and dead or broken branches in the continuous shelterwood cutting systems. The high level of harvest intensity (50\% removal) in the regular shelterwood may have increased sensitivity to wind damage and reduced space for operating the cuts and the less intense continuous cover irregular shelterwood (36\% removal) may have contributed to increase damage to residual trees. The absence of pre-harvest TreM inventory is a limit in our study. Further research is needed to highlight how shelterwood treatments may influence the development of specific TreMs caused by harvest wounds or by post-harvest changes in the stand structure.

The similarity of the Shannon diversity index between the control and the shelterwood treatments could be explained by the slight increase in wounded or senescent trees in the 

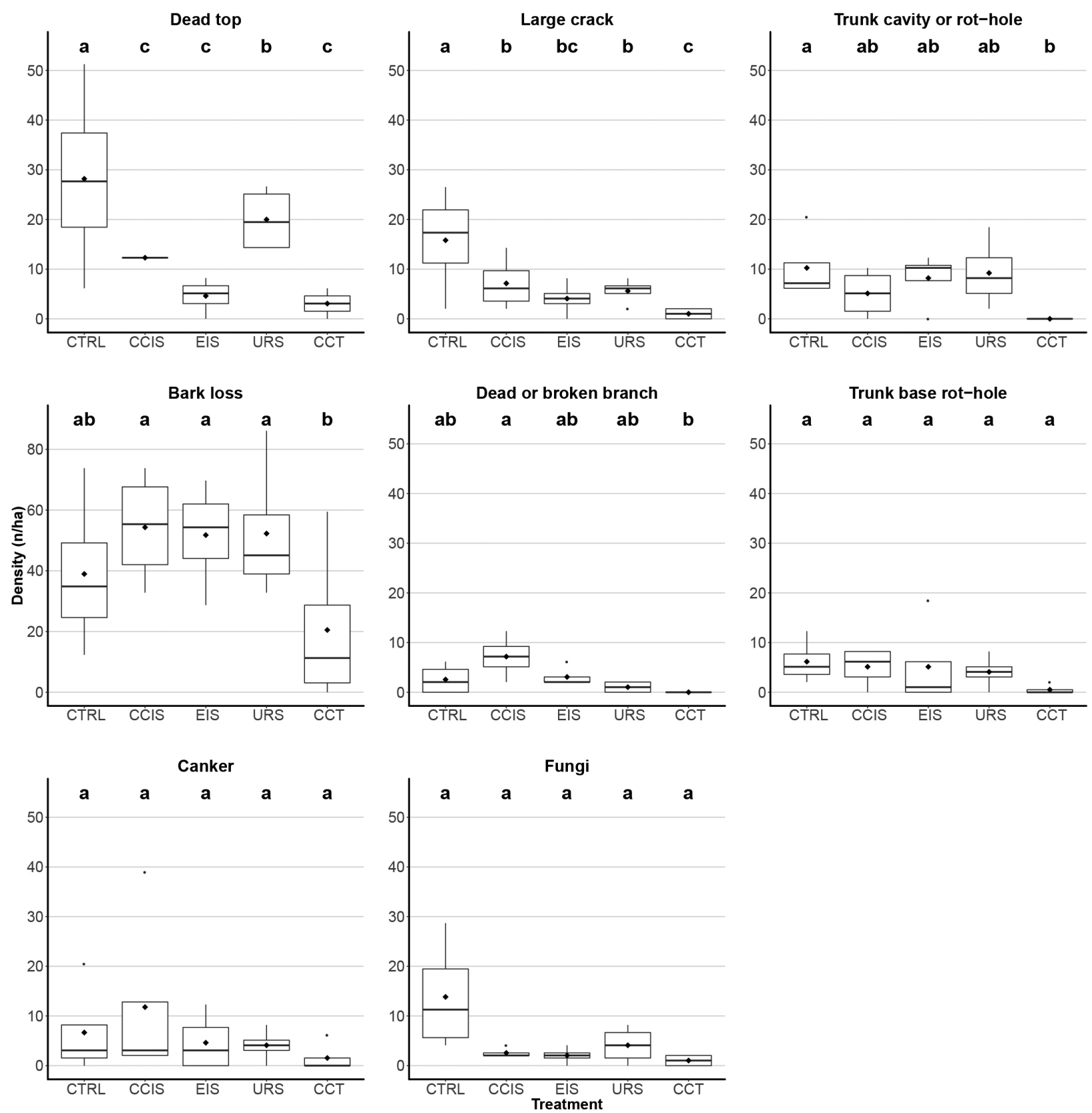

Fig. 3 Boxplot of Shannon index values by TreM classes and cutting treatments. Letters represent significantly different values and diamonds, mean values.CTRL: control; CCIS: continuous irregular shelterwood cutting (RBA: 19 m²/ha); ElS: extended irregular shelterwood cutting (RBA: $17 \mathrm{~m}^{2} / \mathrm{ha}$ ); URS: uniform regular shelterwood cutting (RBA: $15 \mathrm{~m}^{2} / \mathrm{ha}$ ); CCT: clearcut

harvested stands likely to compensate for the removal of trees with large cracks. These changes are moderate but can indicate a potential shift in TreM composition likely to increase with repetitive harvests. Even moderate changes in TreM diversity can have a significant impact on specialized species, which depends on specific TreMs (e.g., Gossner et al. 2016). TreMs associated to a greater decrease in sawlog value may particularly be impacted, to the benefit of TreMs less likely to affect sawlog value. Yet an increase in the density of wounded or senescent trees may counterbalance overall TreM recruitment. Thus, it is hard to determine how the assemblage of TreM types will evolve over the next years. This also highlights the importance of monitoring TreMs on a regular basis in managed stands. When planning cuts in shelterwood systems, defect surveys are performed to ensure that the successive cuts will not cause stand quality depletion. These surveys 
would be also a good opportunity to identify TreMs. Developing a methodology combining defect and TreM surveys could therefore be an efficient solution to monitor changes in TreM abundance and composition over time.

\section{Conclusion}

As predicted, a significant proportion (38\%) of tree defects actually correspond to TreMs because TreMs and defects are often the two faces of the same coin. Accordingly, the biological value of these defects should be acknowledged in sustainable forest management. However, knowledge about TreMs in North American forests is still lacking. Defect surveys could be used as proxies of TreM surveys to facilitate operational assessment in forest management. Yet TreMs are already an indirect approach to monitor biodiversity (Paillet et al. 2018). Using defects as TreM proxies should be then a temporary solution as they are less precise than TreM surveys. The Boulet (2005) methodology could be therefore modified to better integrate TreMs in defect surveys, for example, by 1) monitoring all the TreMs present on trees, 2) including dead wood in the surveys, 3) considering nondefect TreMs, and 4) adapting the TreMs and their thresholds to the northeastern American context, as Larrieu et al. (2018) is a typology for European temperate forests.

Silvicultural systems enabling the maintenance of a continuous forest cover, such as irregular shelterwood, are the most promising for efficient TreM conservation. One third of the main depreciating defects corresponded to TreMs, implying that improving stand quality could be relatively easy to conciliate with biodiversity protection by focusing the harvests on tree-bearing non-TreM defects. Conversely, clearcut systems cause the most important declines in TreMs, and stand rejuvenation strongly limits their recruitment in future decades. However, biodiversity loss associated with each type of TreM in northeastern American mixedwood forests is still relatively unknown. Performing similar TreM research studies in undisturbed stands - an option more achievable in North America than Europe - would be helpful to better understand how to integrate TreMs in managed forests.

As a conclusion, future work on northeastern American TreMs could focus on: (1) constructing a TreM typology relevant to northeastern America, based on pre-existing European and northwestern American typologies; (2) assessing the biodiversity related to each TreM types in northeastern America; and, (3) creating typologies combining defects and TreM surveys to ensure their sustainable management.

\section{Acknowledgements}

We wish to thank Steve Bédard, Stéphane Tremblay, Vincent Roy and Catherine Larouche for their contribution to the development of the Irregular Shelterwood System research program. We are thankful to Éric Michaud and Éric Cantin (Groupement forestier de Portneuf), Scierie Éloi Moisan and the MFFPQ Portneuf-Laurentides Management Unit for their willingness and support regarding the development of irregular shelterwood systems in a field experiment. We are grateful to all the technicians and students who contributed to establish the experiment and collect data over the years, especially Éric Saulnier, Gabrielle Tremblay-Brassard, Gabriel Pilote, Hugo Tremblay and Samantha Martel. Many thanks to Marie-Andrée Vaillancourt and François Guillemette for their helpful comments on earlier versions of this manuscript and to Aimée LeBreton for her copyediting assistance. We also thank Hubert Morin and Nicole Fenton for their support when writing this manuscript, as well as two anonymous reviewers who provided helpful comments that helped us to improve this manuscript. This research is part of Project 142332096 conducted by Direction de la recherche forestière at Ministère des Forêts, de la Faune et des Parcs du Québec.

\section{References}

Bauhus J., K. Puettmann and C. Messier. 2009. Silviculture for old-growth attributes. For. Ecol. Manage. 258(4): 525-537. doi:10.1016/j.foreco.2009.01.053.

Bengston D.N. 1994. Changing forest values and ecosystem management. Soc. Nat. Resour. 7(6): 515-533. doi:10.1080/0894192940 9380885

Bergeron Y., A. Leduc, B.D. Harvey and S. Gauthier. 2002. Natural fire regime: A guide for sustainable management of the Canadian boreal forest. Silva Fenn. 36(January): 81-95.

Blouin J. and J.-P. Berger. 2003. Guide de reconnaissance des types écologiques des régions écologiques $4 \mathrm{~d}$ - Hautes collines de Charlevoix et du Saguenay et $4 \mathrm{e}$ - Plaine du lac Saint-Jean et du Saguenay. Ministère des Ressources naturelles et de la Faune du Québec. Direction des inventaires forestiers, division de la classification écologique et productivité des stations, Québec, QC. 202 p.

Boulet B. 2005. Défauts externes et indices de la carie des arbres. Ministère des Ressources naturelles et de la Faune du Québec. Publications du Québec, QC. 308 p.

Darveau M. and A. Desrochers. 2001. Le bois mort et la faune vertébrée : état des connaissances au Québec. Ministère des Ressources naturelles, Direction de l'environnement forestier (DEF-0199), Québec, QC. 37 p.

DeGraaf R.M. and A.L. Shigo. 1985. Managing cavity trees for wildlife in the Northeast. Northeastern Forest Experimental Station. USDA Forest Service General Technical Report NE-101, 21 p.

Déry S. and M. Leblanc. 2005. Lignes directrices pour l'utilisation de pratiques sylvicoles adaptées rattachées à l'objectif de maintien des forêts mûres et surrannées. Ministère des Ressources naturelles et de la Faune du Québec, Direction de l'environnement forestier (DEF-0255), Québec, QC. 13 p.

Dieler J., E. Uhl, P. Biber, J. Müller, T. Rötzer and H. Pretzsch. 2017. Effect of forest stand management on species composition, structural diversity, and productivity in the temperate zone of Europe. Eur. J. For. Res. 136(4): 739-766. doi:10.1007/s10342-0171056-1.

European Commission. 2015. Natura 2000 and forests. Part I-II. EU publications, Luxembourg, $108 \mathrm{p}$.

Gao T., A. Busse and M. Hedblom. 2015. Reviewing the strength of evidence of biodiversity indicators for forest ecosystems in Europe. Ecol. Indic. 57: 420-434. doi:10.1016/j.ecolind.2015.05.028. Gauthier M-M., S. Bédard and F. Guillemette. 2018. Comparing structural attributes in uneven-aged managed and unmanaged sugar maple stands. Forestry. 92: 67-72. doi:10.1093/forestry/cpy031. Gossner M.M., P. Lade, A. Rohland, N. Sichardt, T. Kahl, J. Bauhus, W.W. Weisser and J.S. Petermann. 2016. Effects of management on aquatic tree-hole communities in temperate forests are mediated by detritus amount and water chemistry. J. Anim. Ecol. 85(1): 213-226. doi:10.1111/1365-2656.12437.

Havreljuk F., A. Achim, D. Auty, S. Bédard and D. Pothier. 2014. Integrating standing value estimations into tree marking guidelines to meet wood supply objectives. Can. J. For. Res. 44(7): 750-759. doi:10.1139/cjfr-2013-0407. 
Holloway G.L., J.P. Caspersen, M.C. Vanderwel and B.J. Naylor. 2007. Cavity tree occurrence in hardwood forests of central Ontario. For. Ecol. Manage. 239(1-3): 191-199. doi:10.1016/j.foreco. 2006.12.004.

Kenefic L.S. and R.D. Nyland. 2007. Cavity Trees, Snags, and Selection Cutting: A Northern Hardwood Case Study. North. J. Appl. For. 24(3): 192-196.

Kutner M.H., C.J. Nachtsheim, J. Neter and W. Li. 2004. Applied linear statistical models. $5^{\text {th }}$ ed. New York: McGraw-Hill/Irwin, $1396 \mathrm{p}$.

Larrieu L., A. Cabanettes and A. Delarue. 2012. Impact of silviculture on dead wood and on the distribution and frequency of tree microhabitats in montane beech-fir forests of the Pyrenees. Eur. J. For. Res. 131: 773-786. doi:10.1007/s10342-011-0551-z.

Larrieu L, A. Cabanettes, A. Brin, C. Bouget and M. Deconchat. 2014. Tree microhabitats at the stand scale in montane beech-fir forests: Practical information for taxa conservation in forestry. Eur. J. For. Res. 133(2): 355-367. doi:10.1007/s10342-013-0767-1.

Larrieu L., A. Cabanettes, N. Gouix, L. Burnel, C. Bouget and M. Deconchat. 2017. Development over time of the tree-related microhabitat profile: The case of lowland beech-oak coppice-with-standards set-aside stands in France. Eur. J. For. Res. 136(1): 37-49. doi:10.1007/s10342-016-1006-3.

Larrieu L., Y. Paillet, S. Winter, R. Bütler, D. Kraus, F. Krumm, T. Lachat, A.K. Michel, B. Regnery and K. Vandekerkhove. 2018. Tree-related microhabitats in temperate and Mediterranean European forests: A hierarchical typology for inventory standardization. Ecol. Indic. 84 (September 2017):194-207. doi:10.1016/j.ecolind. 2017.08.051.

Lindenmayer D., R.J. Hobbs, R. Montague-Drake, J. Alexandra, A. Bennett, M. Burgman, P. Cale, A. Calhoun, V. Cramer, P. Cullen et al. 2008. A checklist for ecological management of landscapes for conservation. Ecol. Lett. 11(1): 78-91. doi:10.1111/j.14610248.2007.01114.x.

Majcen Z., Y. Richard, M. Ménard and Y. Grenier. 1990. Choix des tiges à marquer pour le jardinage d'érablières inéquiennes. Guide technique. Ministère de l'Energie et des Ressources, Direction de la recherche et du développement, service de la recherche appliquée, mémoire n 96, Québec, QC. 96 p.

Martin M. 2014. Identifying and preserving old-growth attributes in mixed forest stands dominated by yellow birch (Betula alleghaniensis) and balsam fir (Abies balsamea) in the context of ecosystem management in Québec. Master's thesis, Université de Lorraine, France, 25 p.

Michel A.K. and S. Winter. 2009. Tree microhabitat structures as indicators of biodiversity in Douglas-fir forests of different stand ages and management histories in the Pacific Northwest, U.S.A. For. Ecol. Manage. 257: 1453-1464. doi:10.1016/j.foreco.2008.11.027.

Michel A.K., S. Winter and A. Linde. 2011. The effect of tree dimension on the diversity of bark microhabitat structures and bark use in Douglas-fir ( Pseudotsuga menziesii var. menziesii). Can. J. For. Res. 41: 300-308. doi:10.1139/X10-207.

MFFP. 2016. [Ministère de la Forêt de la Faune et des Parcs]. Norme d'inventaire écoforestier. Placettes-échantillons temporaires. Direction des Inventaires Forestiers, Ministère de la Forêt, de la Faune et des Parcs, Québec, QC. 171 p.

Nyland R.D. 2002. Silviculture: Concept and Applications. 2nd ed. Waveland Press, New York, 680 p.

OMNR. 2004. [Ontario Ministry of Natural Resources]. Ontario Tree Marking Guide, Version 1.1. Toronto: Ontario Ministry of Natural Ressources. Queen's Printer for Ontario, 252 p.

Ouellet-Lapointe U.P., P. Drapeau, P. Cadieux and L. Imbeau. 2012. Woodpecker Excavations Suitability for and Occupancy by Cavity Users in the Boreal Mixedwood Forest of Eastern Canada. Ecoscience. 19(4): 391-397. doi:10.2980/19-4-3582.
Paillet Y., F. Archaux, S. du Puy, C. Bouget, V. Boulanger, N. Debaive, O. Gilg, F. Gosselin and E. Guilbert. 2018. The indicator side of tree microhabitats: A multi-taxon approach based on bats, birds and saproxylic beetles. J. Appl. Ecol. 55(5): 2147-2159. doi:10.1111/1365-2664.13181

Pinheiro J., D. Bates, S. DebRoy, D. Sarkar and R Core Team. 2016. nlme: Linear and Nonlinear Mixed Effects Models. R package version 3.1-139, URL:https://CRAN.R-project.org/package=nlme. Puettmann K.J., K.D. Coates and C. Messier. 2009. A Critique of Silviculture: Managing for Complexity. Island Press, Washington, D.C. R Core Team. 2016. R: A language and environment for statistical computing. R Foundation for Statistical Computing, Vienna, Austria. URL: https//www.R-project.org.

Raymond P. and S. Bédard. 2017. The irregular shelterwood system as an alternative to clearcutting to achieve compositional and structural objectives in temperate mixedwood stands. For. Ecol. Manage. 398: 91-100. doi:10.1016/j.foreco.2017.04.042.

Raymond P., S. Bédard, V. Roy, C. Larouche and S. Tremblay. 2009. The Irregular Shelterwood System : Review, Classification, and Potential Application to Forests Affected by Partial Disturbances. J. For.(December): 405-413.

Regnery B., Y. Paillet, D. Couvet and C. Kerbiriou. 2013. Which factors influence the occurrence and density of tree microhabitats in Mediterranean oak forests? For. Ecol. Manage. 295: 118-125. doi:10.1016/j.foreco.2013.01.009.

Regniere J. and P. Bolstad. 1994. Statistical Simulation of Daily Air Temperature Patterns Eastern North America to Forecast Seasonal Events in Insect Pest Management. Environ. Entomol. 6(23): 13681380.

Robitaille, A. and J. Saucier. 1978. Paysages régionaux du Québec méridional. Ministère des Ressources naturelles du Québec, Direction de la gestion des stocks forestiers et Direction des relations publiques Publications du Québec, QC. 213 p.

Russel L. 2018. emmeans: Estimated Marginal Means, aka LeastSquares Means. R package version 1.3.4. https://CRAN.R-project .org/package $=$ emmeans

Sarr D.A. and K.J. Puettmann. 2008. Forest management, restoration, and designer ecosystems: Integrating strategies for a crowded planet. Ecoscience. 15(1): 17-26. doi:10.2980/1195-6860(2008) 15[17:FMRADE]2.0.CO; 2.

Shannon C.E. and W. Weaver. 1949. The Mathematical Theory of Communication. University of Illinois Press, Urban, IL, $144 \mathrm{p}$.

Siitonen J. 2012. Microhabitats. In: Stokland J.N., Siitonen J., Jonsson B.G. (eds). Biodiversity in Dead Wood. Ecology, Biodiversity and Conservation, Cambridge University Press, Cambridge, U.K. pp. 150-182.

Smith D.M., B.C. Larson, M.J. Kelty and P.M.S. Ashton. 1997. The Practice of Silviculture: Applied Forest Ecology. John Wiley \& Sons, New York, 537 p.

Stokland J.N., J. Siitonen and B.G. Jonsson. 2012. Biodiversity in dead wood. Cambridge University Press, New York, 509 p.

Vaillancourt M.-A., P. Drapeau, S. Gauthier and M. Robert. 2008. Availability of standing trees for large cavity-nesting birds in the eastern boreal forest of Québec, Canada. For. Ecol. Manage. 255(7): 2272-2285. doi:10.1016/j.foreco.2007.12.036.

Vuidot A., Y. Paillet, F. Archaux and F. Gosselin. 2010. Influence of tree characteristics and forest management on tree microhabitats. Biol. Conserv. 144(1): 441-450. doi:10.1016/j.biocon.2010.09.030. Wickham H. 2016. ggplot2: Elegant Graphics for Data Analysis. Springer-Verlag, New York. URL: https://ggplot2.tidyverse.org. Winter S. and G.C. Möller. 2008. Microhabitats in lowland beech forests as monitoring tool for nature conservation. For. Ecol. Manage. 255(3-4): 1251-1261. doi:10.1016/j.foreco.2007.10.029. 
Appendix S1. Correspondence between the Boulet (2005) defect typology and the TreM typology used in this study for each defect class and number of trees sampled for each defect

\begin{tabular}{|c|c|c|c|}
\hline $\begin{array}{l}\text { Boulet } \\
\text { (2005) } \\
\text { Code }\end{array}$ & Type & Group & Class \\
\hline DB01X & Non-TreM defect & - & Shape defect \\
\hline DB02A & TreM & Top & $\begin{array}{l}\text { Dead or broken } \\
\text { branch }\end{array}$ \\
\hline DB02X & TreM & Top & $\begin{array}{l}\text { Dead or broken } \\
\text { branch }\end{array}$ \\
\hline DB03X & Non-TreM defect & - & Clump shoot \\
\hline DB04X & Non-TreM defect & - & Bark wound \\
\hline DB05A & TreM & Trunk & Bark loss \\
\hline DB05X & TreM & Trunk & Bark loss \\
\hline DB06A & TreM & Trunk & Bark loss \\
\hline DB06E & TreM & Trunk & Bark loss \\
\hline DB06X & TreM & Trunk & Bark loss \\
\hline DB07A & TreM & Trunk & Bark loss \\
\hline DB07X & TreM & Trunk & Bark loss \\
\hline DB08X & TreM & Small & Epicormic shoots \\
\hline DB09A & Non-TreM defect & - & Shape Defect \\
\hline DB09E & Non-TreM defect & - & Shape defect \\
\hline DB09X & Non-TreM defect & - & Shape defect \\
\hline DB10X & Non-TreM defect & - & Shape defect \\
\hline DB11X & Non-TreM defect & - & Low top mortality \\
\hline $\mathrm{DB} 12 \mathrm{X}$ & Non-TreM defect & - & Shape defect \\
\hline DB13X & TreM & Small & Burr \\
\hline DB14A & TreM & Small & Burr \\
\hline DB14X & TreM & Small & Burr \\
\hline DB17X & Non-TreM defect & - & Shape defect \\
\hline DB18A & Non-TreM defect & - & Shape Defect \\
\hline DB18X & Non-TreM defect & - & Shape Defect \\
\hline DB19X & Non-TreM defect & - & Shape defect \\
\hline DB20A & TreM & Trunk & Bark loss \\
\hline DB20E & TreM & Trunk & Bark loss \\
\hline DB20X & TreM & Trunk & Bark loss \\
\hline DB21A & TreM & Trunk & Bark loss \\
\hline DB21E & TreM & Trunk & Bark loss \\
\hline DB21X & TreM & Trunk & Bark loss \\
\hline DB30E & Non-TreM defect & - & Shape defect \\
\hline DB30X & Non-TreM defect & - & Shape defect \\
\hline DB31X & Non-TreM defect & - & Clump shoot \\
\hline DB32X & TreM & Top & $\begin{array}{l}\text { Dead or broken } \\
\text { branch }\end{array}$ \\
\hline DB33E & TreM & Top & Dead top \\
\hline DB33X & TreM & Top & Dead top \\
\hline DB34E & TreM & Top & Dead top \\
\hline DB34X & TreM & Top & Dead top \\
\hline DB35A & TreM & Trunk & Bark loss \\
\hline DB35E & TreM & Trunk & Bark loss \\
\hline DB35X & TreM & Trunk & Bark loss \\
\hline DB36A & TreM & Trunk & Bark loss \\
\hline
\end{tabular}

\section{Boulet}

(2005)

Code

Type

DB36X TreM

DB38A TreM

DB38X TreM

DB40E Non-TreM defect

DB40X Non-TreM defect

DB41X Non-TreM defect -

DB42X TreM Top

Group Class

$\mathrm{N}$ sampled

DB43X Non-TreM defect -

Trunk Bark loss 2

EN01X Non-TreM defect

EN02E TreM

Small Burr

Small Burr

- $\quad$ Shape defect

Shape defect

Shape defect 5

Top Dead or broken 2

- Shape defect 5

17

18

53

EN02X TreM

Cavity

Small cavity

46

Trunk cavity or 26 rot-hole

Cavity Trunk cavity or 5

EN03X TreM

EN04A TreM

Cavity Trunk cavity or 4 rot-hole

Cavity Trunk cavity or 26 rot-hole

EN04X TreM

Cavity Trunk cavity or 3

EN05E Non-TreM defect rot-hole

Small cavity

Small cavity

EN33A Non-TreM defect -

EN33X Non-TreM defect

FE01X Non-TreM defect

FE02A TreM

E02E TreM

FE02X

FE04A

FE04X

FE06A TreM

FE06E TreM

FE06X TreM

2 FE07X

62 FE08A

Non-TreM defect

Non-TreM defect

FE08X

Non-TreM defect

TreM

FE10X TreM

115 FE11X TreM

60 FE12X TreM

1 FE13E
Small cavity

Small cavity

Small cavity

Small cavity

Dead or broken branch

Small cavity

Small cavity

Non-TreM defect

$-$

Shape defect

Trunk

Large crack

Trunk

Large crack

Small crack

Small crack

Healed wound

Healed wound

Non-TreM defect

$-$

Non-TreM defect
Large crack

Trunk

Trunk

Trunk

Large crack

Large crack

Healed wound

Healed wound

Healed wound

Large crack

Large crack

Large crack

Large crack

Healed wound 
Boulet

\begin{tabular}{|c|c|c|c|c|c|c|c|c|}
\hline FE13X & Non-TreM defect & - & Healed wound & 1 & NC07X & Non-TreM defect & - & Small canker \\
\hline FE15X & Non-TreM defect & - & Bark wound & 1 & NC11X & TreM & Trunk & Bark shelter \\
\hline FE16A & Non-TreM defect & - & Clump shoot & 2 & NC30XC & TreM & Trunk & Canker \\
\hline FE16E & Non-TreM defect & - & Clump shoot & 4 & NC32E & TreM & Trunk & Bark shelter \\
\hline FE16X & Non-TreM defect & - & Clump shoot & 2 & NC33X & Non-TreM defect & - & Bark wound \\
\hline FE30E & Non-TreM defect & - & Small crack & 1 & PR01E & TreM & Cavity & Trunk base rot-hole \\
\hline FE30X & Non-TreM defect & - & Small crack & 17 & PR01X & TreM & Cavity & Trunk base rot-hole \\
\hline FE31A & Non-TreM defect & - & Small crack & 5 & PR02E & Non-TreM defect & - & Healed wound \\
\hline FE31X & Non-TreM defect & - & Small crack & 11 & PR02X & Non-TreM defect & - & Healed wound \\
\hline FE33X & TreM & Trunk & Large crack & 4 & PR03A & TreM & Cavity & Trunk base rot-hole \\
\hline FE34X & Non-TreM defect & - & Small crack & 1 & PR03E & TreM & Cavity & Trunk base rot-hole \\
\hline FE35E & TreM & Trunk & Large crack & 453 & PR03X & TreM & Cavity & Trunk base rot-hole \\
\hline FE35X & TreM & Trunk & Large crack & 1 & PR04E & Non-TreM defect & - & Healed wound \\
\hline FE36A & TreM & Trunk & Fork split & 2 & PR04X & Non-TreM defect & - & Healed wound \\
\hline FE36E & Non-TreM defect & - & Healed wound & 1 & PR05X & Non-TreM defect & - & Healed wound \\
\hline FE36X & Non-TreM defect & - & Healed wound & 2 & PR07A & Non-TreM defect & - & Wounded or \\
\hline HP01A & Non-TreM defect & - & Low top mortality & 14 & & & & rotten root \\
\hline HP01E & Non-TreM defect & - & Low top mortality & 2 & PR07E & Non-TreM defect & - & Wounded or \\
\hline HP01X & Non-TreM defect & - & Low top mortality & 5 & & & & \\
\hline HP02A & TreM & Top & Dead top & 1 & PR07X & Non-TreM defect & - & $\begin{array}{l}\text { Wounded or } \\
\text { rotten root }\end{array}$ \\
\hline HP02E & TreM & Top & Dead top & 8 & PR30E & TreM & Cavity & Trunk base rot-hole \\
\hline HP02S & TreM & Top & Dead top & 4 & PR31A & TreM & Cavity & Trunk base rot-hole \\
\hline HP02X & TreM & Top & Dead top & 2 & PR31X & TreM & Cavity & Trunk base rot-hole \\
\hline HP03E & TreM & Top & Dead top & 2 & PR32A & Non-TreM defect & - & Wounded or \\
\hline HP03X & TreM & Top & Dead top & 1 & & & & rotten root \\
\hline HP04X & TreM & Top & Dead top & 4 & PR32E & Non-TreM defect & - & Wounded or \\
\hline HP06A & TreM & Top & Dead top & 7 & & & & rotten root \\
\hline HP06E & TreM & Top & Dead top & 1 & PR32X & Non-TreM defect & - & Wounded or \\
\hline HP07X & TreM & Top & Dead top & 13 & & & & \\
\hline HP11A & TreM & Top & Dead or broken & 2 & SP06X & TreM & Small & Fungi \\
\hline & & & branch & & SP09A & TreM & Small & Fungi \\
\hline HP11E & TreM & Top & Dead or broken & 7 & SP10A & TreM & Small & Fungi \\
\hline & & & branch & & SP10X & TreM & Small & Fungi \\
\hline HP11X & TreM & Top & Dead or broken & 3 & SP12S & TreM & Small & Fungi \\
\hline & & & & & SP12X & TreM & Small & Fungi \\
\hline HP12X & Non-TreM defect & - & Shape defect & 3 & SP14A & TreM & Small & Fungi \\
\hline HP33A & Non-TreM defect & - & Low top mortality & 1 & SP15X & TreM & Small & Fungi \\
\hline HP34E & Non-TreM defect & - & Low top mortality & 109 & SP16X & TreM & Small & Fungi \\
\hline HP34X & Non-TreM defect & - & Low top mortality & 9 & SP34X & TreM & Small & Fungi \\
\hline NC01A & Non-TreM defect & - & Bark wound & 40 & SP36X & TreM & Small & Fungi \\
\hline NC01X & Non-TreM defect & - & Bark wound & 5 & VP01A & Non-TreM defect & - & Insect holes \\
\hline NC02X & Non-TreM defect & - & Bark wound & 6 & VP02X & Non-TreM defect & - & Insect holes \\
\hline NC05A & Non-TreM defect & - & Bark wound & 2 & VP07X & Non-TreM defect & - & Insect holes \\
\hline NC07A & TreM & Trunk & Canker & 31 & VP33E & Non-TreM defect & - & Shape defect \\
\hline NC07E & TreM & Trunk & Canker & 6 & & & & \\
\hline
\end{tabular}



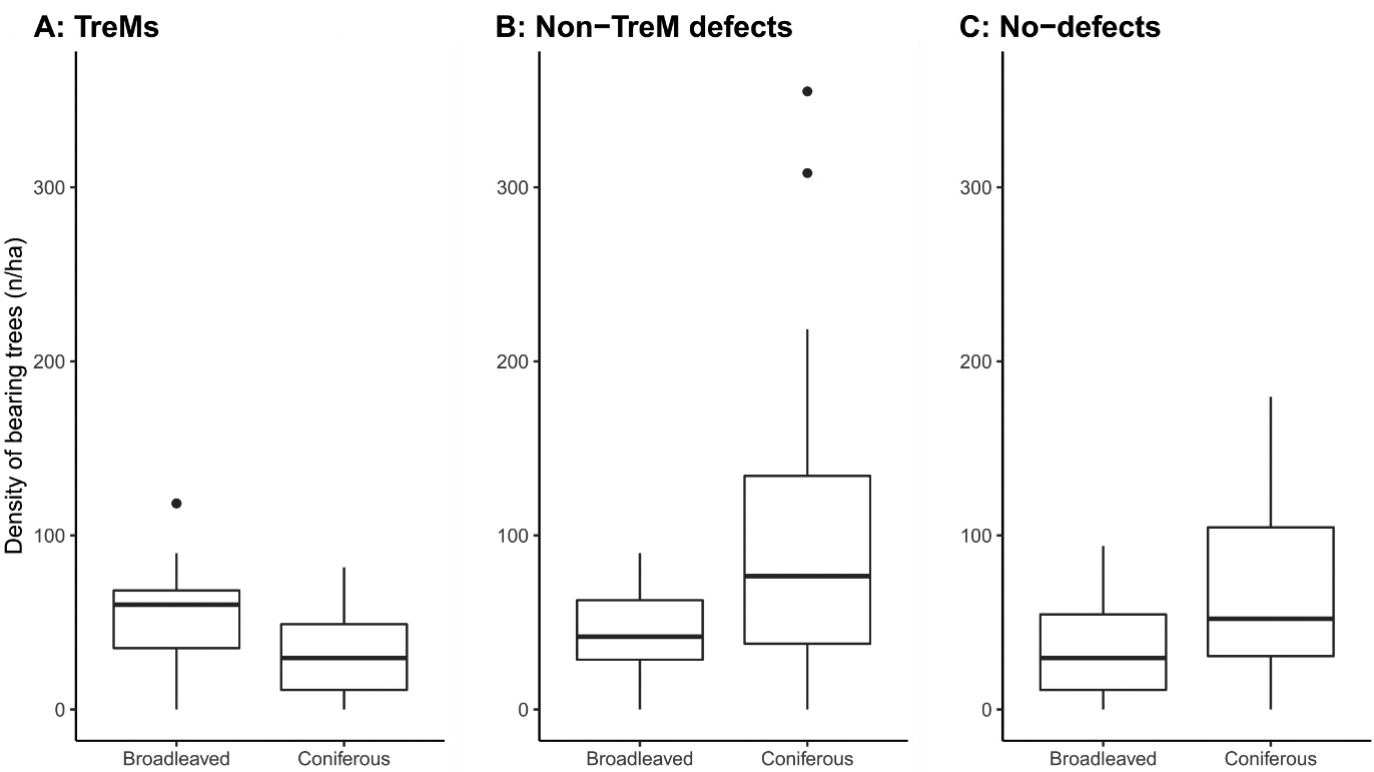

Appendix S3. DBH (Mean \pm Standard-error, unit: $\mathrm{cm}$ ) of tree-bearing TreMs according to TreM class and tree species. Italics indicate values obtained from single observations and blanks, no observation.

\begin{tabular}{|c|c|c|c|c|c|c|c|}
\hline Category & Class & All species & Yellow birch & Balsam fir & Paper birch & Red spruce & Red maple \\
\hline \multirow[t]{2}{*}{ Cavity } & Trunk cavity or rot-hole & $20,23 \pm 7,78$ & $24,36 \pm 9,4$ & - & $16,72 \pm 3,78$ & - & $17,43 \pm 4,77$ \\
\hline & Trunk base rot-hole & $20,04 \pm 7,1$ & $22,36 \pm 7,36$ & $12,3 \pm 1,36$ & $15,3 \pm 2,4$ & $23,5 \pm 6,05$ & $17,93 \pm 6,81$ \\
\hline \multirow[t]{5}{*}{ Trunk } & Canker & $17,44 \pm 7,25$ & $31,6 \pm 0$ & - & $14,7 \pm 0$ & $22,06 \pm 7,85$ & $14,61 \pm 5,12$ \\
\hline & Bark shelter & $17,95 \pm 8,73$ & $24,8 \pm 5,94$ & $9,4 \pm 0$ & $12,8 \pm 0$ & - & - \\
\hline & Bark loss & $15,13 \pm 5,36$ & $17,38 \pm 7,06$ & $13,61 \pm 3,45$ & $14,14 \pm 5,11$ & $19,65 \pm 7,84$ & $14,25 \pm 3,94$ \\
\hline & Large crack & $20,59 \pm 8,7$ & $26,01 \pm 10,06$ & - & $13,9 \pm 0$ & $28,84 \pm 13,55$ & $18,51 \pm 6,72$ \\
\hline & Fork split & $35,75 \pm 6,15$ & - & - & $35,75 \pm 6,15$ & - & - \\
\hline \multirow[t]{2}{*}{ Top } & Dead or broken branch & $19,64 \pm 13,74$ & $34,82 \pm 25,65$ & $11,93 \pm 1,88$ & $15,94 \pm 6,5$ & $10,6 \pm 1,27$ & $20,54 \pm 6,39$ \\
\hline & Dead top & $14,12 \pm 4,28$ & $15,44 \pm 5,31$ & $12,64 \pm 3,4$ & $12,81 \pm 3,57$ & $15,09 \pm 4,29$ & $16,28 \pm 5,78$ \\
\hline \multirow[t]{3}{*}{ Small } & Epicormic shoots & $13,4 \pm 0$ & - & $13,4 \pm 0$ & - & - & - \\
\hline & Burr & $24,65 \pm 10,85$ & $34 \pm 0$ & $15,4 \pm 0$ & - & $32,25 \pm 19,3$ & $20,83 \pm 5,91$ \\
\hline & Fungi & $19,28 \pm 8,88$ & $23,31 \pm 12,56$ & $23,1 \pm 0$ & $33,3 \pm 0$ & $48,7 \pm 0$ & $17,19 \pm 5,98$ \\
\hline
\end{tabular}

